\title{
Analisa Traffic Data Esp8266 Pada Kontrol Dan Monitoring Daya Lisrik Menggunakan Aplikasi Blynk Berbasis Arduino Nano
}

\author{
Fadhli Palaha $^{1}$, Ermawati ${ }^{2}$, Machdalena ${ }^{3}$, Dan Engla Harda Arya 4 \\ ${ }^{1234}$ Sekolah Tinggi Teknologi Pekanbaru \\ Jalan Dirgantara No 04 Arengka Pekanbaru, kota kode pos \\ Corresponding author's e-mail: fadhlyyy@yahoo.com
}

\begin{abstract}
Abstrak - Android atau Smartphone adalah handphone pintar yang fungsinya tidak hanya sebagai alat komunikasi tetapi juga bisa sebagai media pencari informasi melalui internet. Hampir disetiap rumah sudah memakai jaringan Wifi sebagai pengakses internet. dengan bantuan jaringan Wifi ini dimanfaatkan sebagai kelistrikan seperti di rumah yang bisa dikontrol dari dimonitoring kelistrikannya pada saat berada diluar rumah kontrol dan monitoring juga. Dengan melihat cara mengontrol dan memonitoring daya lisrik pada rumah saat sekarang ini tidak efesien dan efektif. penelitian ini dilakukan rekayasa traffic paket data menggunakan modul wifi ESP8266 pada jaringan perangkat IoT untuk mengetahui berapa cepat waktu capture paket datanya mengunakan wifi untuk control dan monitoring daya listrik rumah berdasarkan TIPHON. Dengan hasil dari penelitian dalam penggunaan jaringan jaringan 4G LTE waktu eksekusi yang lebih cepat di bandingkan 3G serta pengukuran parameter QoS dalam jaringan saat melakukan pengiriman data pada HMI dan hardware yaitu rata rata besar paket yang dikirim hanya sekitar 560 bit (Uplink) dan 430 bit (Downlink). Throughput yang terbaca juga sangat kecil dengan rata rata $2.9 \mathrm{kbps}$ (Uplink) dan $2.2 \mathrm{kbps}$ (Downlink). Dan ini bisa dikatakan itu tidak terjadi packet loss saat pengirim data.

Kata kunci: Android ,Arduino Nano, Blynk,, Internet of Thing, MCU ESP8266.
\end{abstract}

\section{Pendahuluan}

Android atau Smartphone adalah handphone pintar yang fungsinya tidak hanya sebagai alat komunikasi tetapi juga bisa sebagai media pencari informasi melalui internet[1]. Agar bisa mengakses internet tentu perlu adanya suatu jaringan internet atau paket data internet untuk smartphone tersebut. Dalam kehidupan sekarang ini hampir disetiap rumah sudah memakai jaringan Wifi sebagai pengakses internet tersebut, karena dilihat dari segi biaya yang bisa dipakai bersama-sama dan kuota internet yang tidak dibatasi[2]. Dengan memperhatikan hal tersebut, ternyata jaringan Wifi ini tidak hanya bisa digunakan sebagai internet saja tetapi bagi orang yang tahu bisa juga dimanfaatkan sebagai kontrol dan monitoring daya listrik di rumah dengan menggunakan aplikasi blynk pada smartphone[3].

Jadi dengan bantuan jaringan Wifi ini dimanfaatkan sebagai kontrol dan monitoring kelistrikan seperti di rumah yang bisa dikontrol dari dimonitoring kelistrikannya pada saat berada diluar rumah juga[4]. Dengan melihat cara mengontrol dan memonitoring daya lisrik pada rumah saat sekarang ini tidak efesien dan efektif di karenakan pengendalian dan memonitoring daya listrik masih dilakukan secara manual seperti menghidupmatikan lampu langsung ke saklarnya dan untuk memonitoring daya listrik terpakai mesti pergi berjalan untuk melihat Kwh meter PLN nya[5].

Pada penelitian ini dilakukan rekayasa traffic paket data menggunakan modul wifi ESP8266 pada jaringan perangkat IoT untuk mengetahui berapa cepat waktu capture paket datanya mengunakan wifi untuk control dan monitoring daya listrik rumah berdasarkan TIPHON (Telecommunications and Internet Protocol Harmonization Over Network)[6].

\section{Tinjauan Pustaka}

\subsection{Listrik Bolak-Balik (AC)}

Sumber Listrik bolak-balik dapat menghasilkan tegangan dan arus dengan polaritas dan nilai besaran yang selalu berubah-ubah secara periodik. sumber Listrik bolak-balik biasanya digambarkan dalam bentuk gelombang secara sinus[7]. Nilai tegangan dan arus Nilai tegangan dan arus bolak-balik biasanya dinyatakan dalam bentuk RMS (Root Mean Square).

Pada dasarnya nilai magnitudo tegangan dan arus selalu berubah setiap waktu. Untuk menyatakannya dalam bilangan konstan maka diambil nilai RMS yaitu kuadrat rata-rata dari nilai puncak tegangan ataupun arus tersebut[8]. Untuk menghitung perubahan arus dan tegangan RMS dapat dihitung dengan persamaan :

$$
\begin{gathered}
\text { Vrms }=\frac{1}{\sqrt{2}} V \max \\
I r m s=\frac{1}{\sqrt{2}} I \max
\end{gathered}
$$


Dimana nilai V max dan I max adalah nilai amplitudo maksimum dari sinyal yang disampling .

\subsection{Segitiga Daya}

Segitiga daya merupakan segitiga yang menggambarkan hubungan matematika antara tipe-tipe daya yang berbeda (Apparent Power, Active Power dan Reactive Power) berdasarkan prinsip trigonometri seperti pada Gambar 1[9].

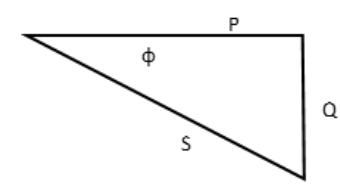

Gambar 1. Segitiga Daya

$$
\begin{aligned}
& \text { Dimana : } \\
& \mathrm{P}=\text { Daya Aktif (Watt) } \\
& \mathrm{Q}=\text { Daya Reaktif (VAR) } \\
& \mathrm{S}=\text { Daya Semu (VA) } \\
& \varphi=\text { Sudut antara P dan S }
\end{aligned}
$$

Daya Aktif adalah daya nyata yang dikonsumsi dalam suatu rangkaian listrik AC. Daya aktif diukur dalam satuan Joule/detik atau Watt

$$
\begin{aligned}
& P=V \cdot I \cdot \cos \varphi \\
& \text { Dimana }: \\
& \mathrm{P}=\text { Daya Aktif }(\mathrm{W}) \\
& \mathrm{V}=\text { Tegangan }(\mathrm{V}) \\
& \mathrm{I}=\text { Arus }(\mathrm{A}) \\
& \operatorname{Cos} \varphi=\text { Faktor Daya }
\end{aligned}
$$

Daya Reaktif adalah daya yang tidak digunakan oleh beban.yangdihasilkan oleh beban kapasitif ataupun beban induktif. Daya reaktif ini memiliki satuan VAR.

$$
\begin{aligned}
& Q=V \cdot I \cdot \sin \varphi \\
& \text { Dimana }: \\
& \mathrm{Q}=\text { Daya Reaktif }(\mathrm{VAR}) \\
& \mathrm{V}=\text { Tegangan }(\mathrm{V}) \\
& \mathrm{I}=\operatorname{Arus}(\mathrm{A})
\end{aligned}
$$

Daya Semu adalah total daya yang harus disuplai oleh sumber ke rangkaian beban. dengan simbol $\mathrm{S}$ dan memiliki satuan VA.

$$
S=V . I
$$

Dimana :

$$
\begin{aligned}
& \mathrm{S}=\text { Daya Semu (VA) } \\
& \mathrm{V}=\text { Tegangan }(\mathrm{V}) \\
& \mathrm{I}=\text { Arus }(\mathrm{A})
\end{aligned}
$$

Sesuai dengan gambar 2.1 yang menunjukkan hubungan antara daya aktif (P), daya reaktif (Q) dan daya semu (S). Maka daya semu juga dapat dihitung menggunakan rumus

$$
S=\sqrt{P^{2}+Q^{2}}
$$

\subsection{ESP8266 Node MCU}

ESP8266 adalah modul wifi dimana didalamnya sudah terdapat processor, memori dan akses ke GPIO. Hampir sama dengan arduino namun ESP8266 memiliki keunggulan yaitu dapat membuat koneksi TCP/IP dengan perangkat wifi yang dimilikinya[11]. Karena fiturnya sudah lengkap layaknya chip mikrokontroller, maka modul ini dapat berdiri sendiri tanpa bantuan mikrokontroller lagi. 


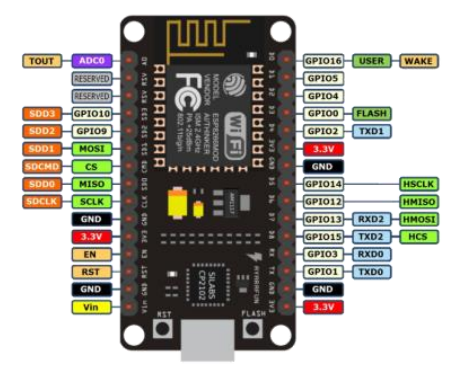

Gambar 2 Konfigurasi ESP8266

\subsection{Arduino Nano}

Arduino Nano adalah salah satu board pengembangan mikrokontroler yang memiliki ukuran kecil, lengkap dan dan praktis jika kita menggunakan breadboard dalam project kita[14]. Arduino Nano diciptakan dengan basis mikrokontroler ATmega328 (untuk Arduino Nano versi 3.x) atau ATmega 168 (untuk Arduino versi 2.x)[12].

\subsection{Blynk}

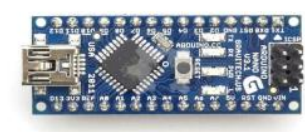

Blynk adalah platform layanan penyedia server untuk mendukung project project IoT. Layanan ini memiliki antar muka mobile user yang dijalankan pada Android ataupun iOS. Blynk diciptakan dengan tujuan untuk control dan monitoring hardware secara jarak jauh menggunakan komunikasi data internet ataupun intranet (jaringan LAN)[13]. Kemampuan untuk menyimpan data dan menampilkan data secara visual baik menggunakan angka, warna ataupun grafis semakin memudahkan dalam pembuatan project dibidang Internet of Things. Terdapat 3 komponen utama Blynk, dan hubungan antara ketiga komponen ini seperti pada gambar

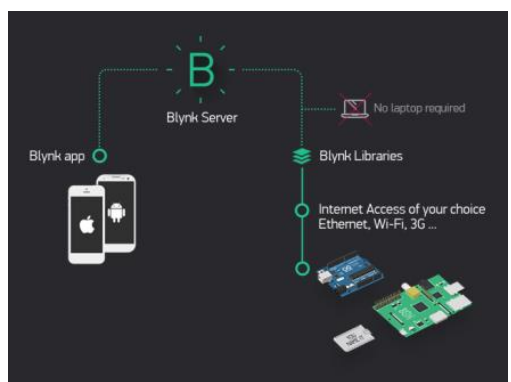

Gambar 4. Hubungan 3 Komponen Utama Blynk

\section{Metode Penelitian}

Untuk menguji performa sistem saat terjadi nya pengiriman data ke jaringan internet maka akan diuji menggunakan software wireshark. Aplikasi ini umum digunakan sebagai alat troubleshoot pada jaringan yang bermasalah, selain itu juga biasa digunakan untuk pengujian software karena kemampuannya untuk membaca konten dari tiap paket trafik data.

ESP8266 adalah :

Parameter untuk menguji sistem pengiriman data pada sisi HMI smartphone dan juga Perangkat

1. Latency/Delay

2. Jitter

3. Throughput

4. Packet Loss

\subsection{Flow Chart Program}

Perancangan system ini terdapat dua program yang harus dibuat yaitu pada NodeMCU ESP8266 dan juga Arduino Nano. Flow chart program pada Node MCU ESP8266 ada pada gambar 5 dan 6 dibawah ini : 


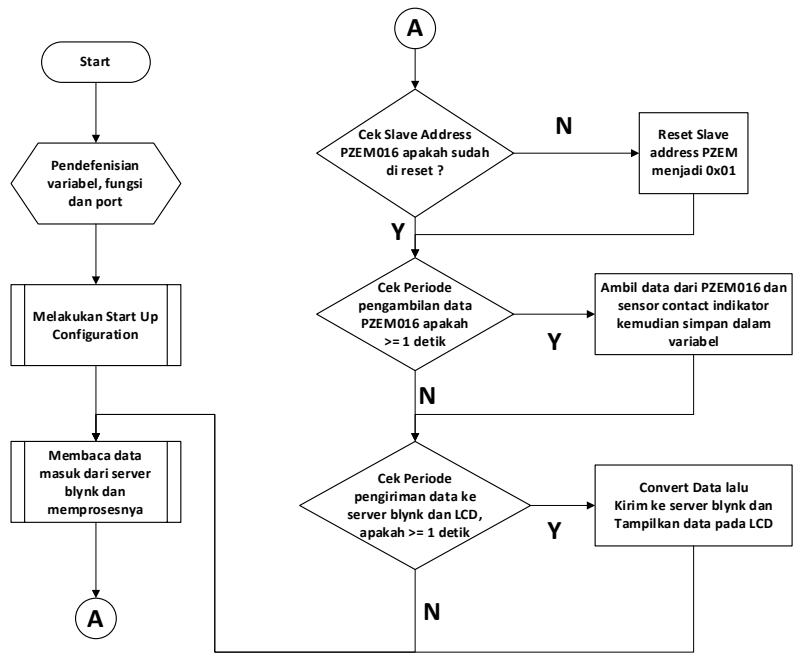

Gambar 5. Flow chart program utama Node MCU ESP8266

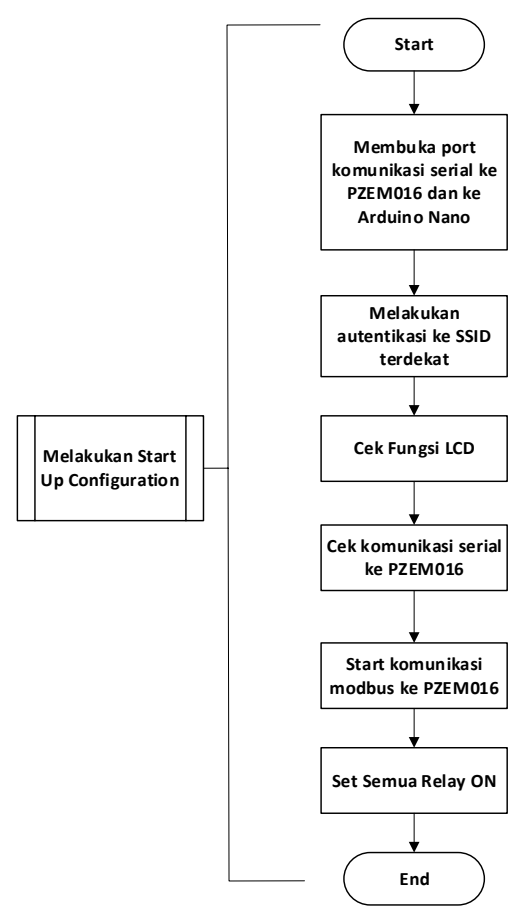

Gambar 6. Flow chart sub program 1 dari program utama Node MCU. 


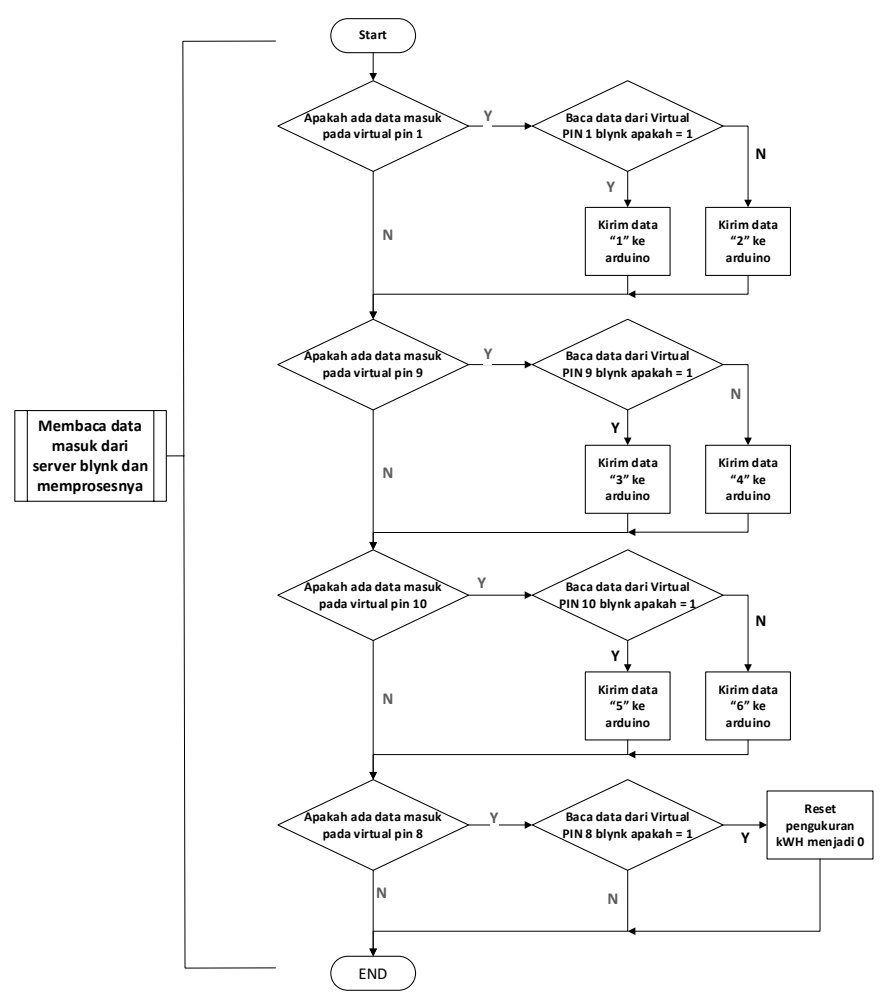

Gambar 7. Flow chart sub program 2 dari program utama Node MCU.

Beralih ke Arduino Nano, Flow chart algoritma program untuk arduino nano adalah pada gambar 8.

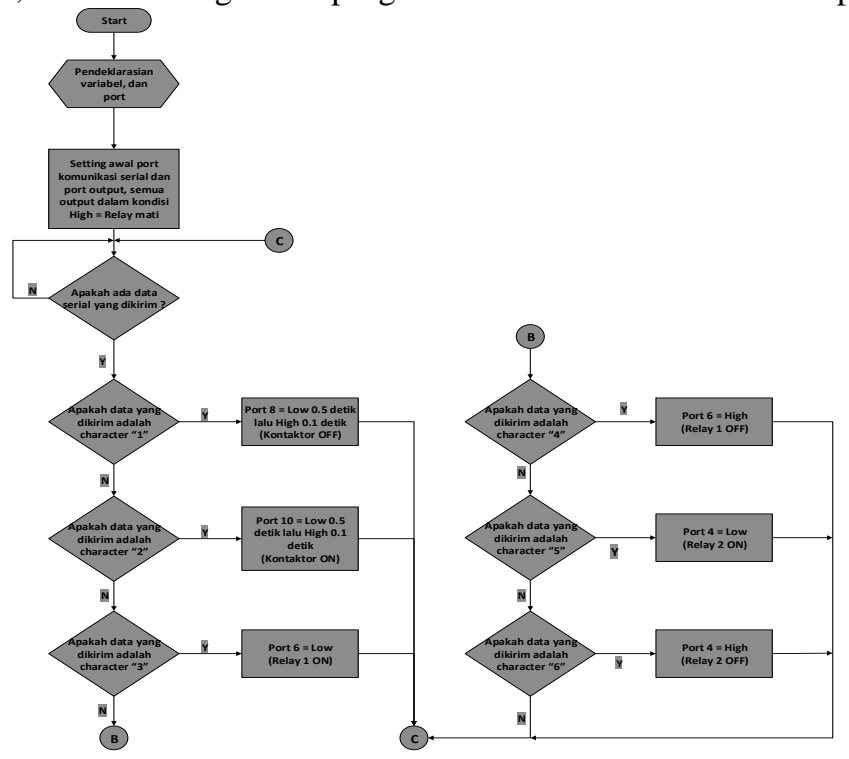

Gambar 8. Flow chart program untuk Arduino Nano

\section{Hasil dan Pembahasan}

\subsection{Hasil Pengujian Pengiriman Data}

Tujuan dari pengujian ini adalah untuk melihat kinerja sistem saat terjadi pengiriman data. Traffic data yang akan dikirim ke server blynk baik dari NodeMCU dan smartphone android akan di monitor menggunakan software wireshark. 
Pengujian dilakukan dengan dua skenario dengan transport data yang berbeda yaitu menggunakan jaringan LTE Telkomsel dan jaringan LTE H3I. Traffic data dipantau pada dua bagian yaitu hardware dan HMI. Adapun skema hirarki pengujian pengiriman data ini terdapat pada gambar berikut

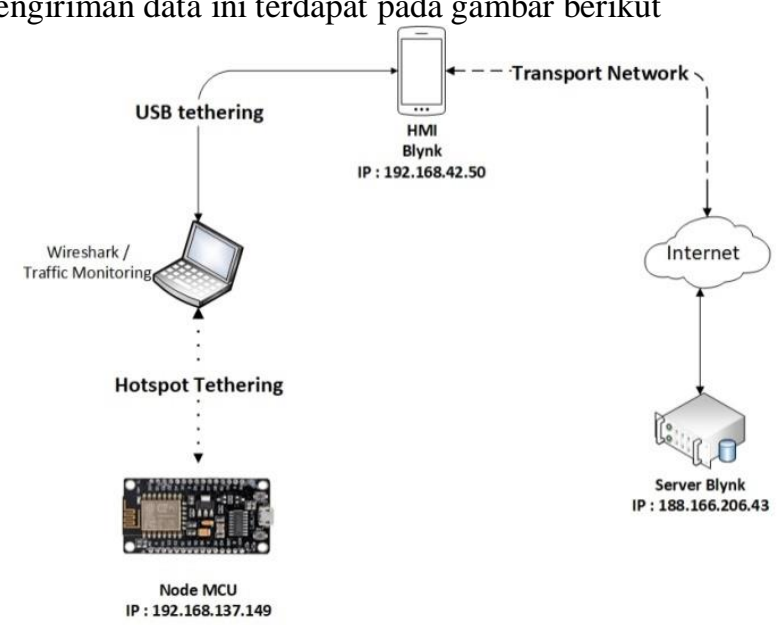

Gambar 9. Hirarki pengujian pengiriman data

Laptop yang sudah terinstall software wireshark dijadikan gateway untuk traffic data Node MCU agar memudahkan dalam memonitoring traffic datanya tanpa harus memecahkan enkripsi ketika di dihubungkan dalam satu network wifi. Parameter yang menjadi standar pengukuran integritas dari pengiriman data diantarnya adalah delay, jitter, throughput dan Packet Loss. Contoh proses capture traffic menggunakan wireshark seperti gambar berikut

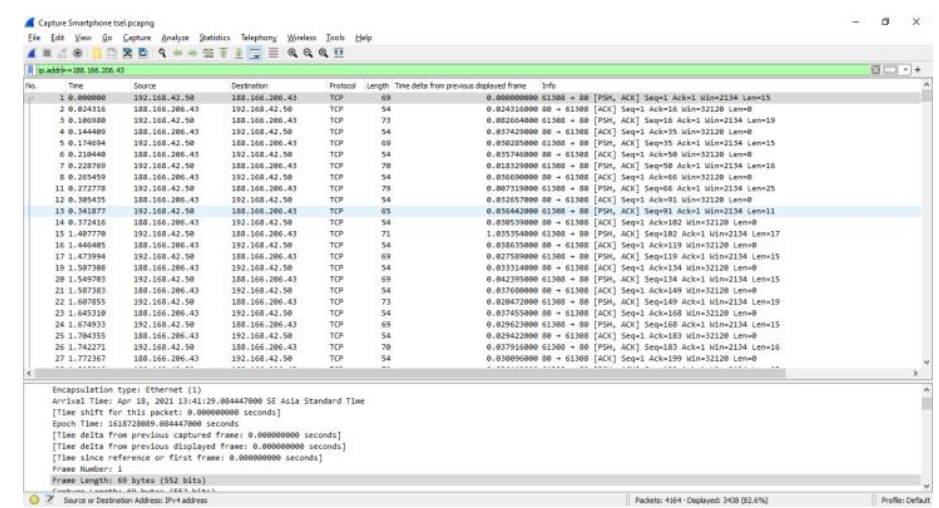

Gambar 10. Proses capture traffic menggunakan wireshark

Data yang sudah dicapture kemudian diolah menggunakan microsoft excel untuk dihitung masing masing nilai dari keempat parameter dengan dua skenario transport data. Berdasarkan TIPHON (Telecommunications and Internet Protocol Harmonization Over Network) yang merupakan standar penilaian parameter QoS yang dikeluarkan oleh badan standar ETSI (European Telecommunications Standards Institute). Standarisasi nilai delay adalah sebagai berikut:

Tabel 1. Kategori Delay (Latency)

\begin{tabular}{|l|l|l|}
\hline Kategori Latensi & Besar Delay & Indeks \\
\hline Sangat Bagus & $<150 \mathrm{~ms}$ & 4 \\
\hline Bagus & $150 \mathrm{~ms} \mathrm{~s} / \mathrm{d} 300 \mathrm{~ms}$ & 3 \\
\hline Sedang & $300 \mathrm{~ms} \mathrm{~s} / \mathrm{d} 450 \mathrm{~ms}$ & 2 \\
\hline Jelek & $>450 \mathrm{~ms}$ & 1 \\
\hline
\end{tabular}

Delay dapat dihitung menggunakan rumus

$$
\text { Rata-rata Delay }=\frac{\text { Total Delay }}{\text { Total Paket yang diterima }}
$$


Untuk standarisasi nilai jitter bersarkan TIPHON adalah sebagai berikut

Tabel 2. Kategori Jitter

\begin{tabular}{|l|l|l|}
\hline Kategori Jitter & Jitter & Indeks \\
\hline Sangat Bagus & $0 \mathrm{~ms}$ & 4 \\
\hline Bagus & $0 \mathrm{~ms} \mathrm{~s} / \mathrm{d} 75 \mathrm{~ms}$ & 3 \\
\hline Sedang & $75 \mathrm{~ms} \mathrm{~s} / \mathrm{d} 125 \mathrm{~ms}$ & 2 \\
\hline Jelek & $125 \mathrm{~ms} \mathrm{~s} / \mathrm{d} 225 \mathrm{~ms}$ & 1 \\
\hline
\end{tabular}

Jitter dapat dihitung dengan rumus

$$
\text { Jitter }=\frac{\text { Total variasi delay }}{\text { Total Paket yang diterima }-1}
$$

Total variasi delay diperoleh dari penjumlahan :

$$
(\text { delay } 2-\operatorname{delay} 1)+(\text { delay } 3-\operatorname{delay} 2)+\ldots .(\text { delay } n-\operatorname{delay}(n-1))
$$

Untuk standarisasi nilai Packet loss berdasarkan TIPHON adalah sebagai berikut

Tabel 3. Kategori Packet Loss

\begin{tabular}{|l|l|l|}
\hline Kategori Degredasi & Packet Loss $(\boldsymbol{\%})$ & Indeks \\
\hline Sangat Bagus & 0 & 4 \\
\hline Bagus & 3 & 3 \\
\hline Sedang & 15 & 2 \\
\hline Jelek & 25 & 1 \\
\hline
\end{tabular}

Packet Loss dapat dihitung menggunakan rumus

Packet Loss $=\underline{\text { Paket data yang dikirim }- \text { paket data yang diterima }} \times 100 \%$

Paket data yang dikirim

Sedangkan Throughput bisa dihitung menggunakan rumus

\section{Throughput $=\underline{\text { Paket data yang diterima }}$ \\ Lama pengamatan}

Pengamatan dilakukan kurang lebih selama 330 detik atau 5.5 menit pada saat traffic normal antara jam 10 - 11 pagi. Data yang di hasilkan saat capture traffic ada pada tabel 4 dan 5

\begin{tabular}{|c|c|c|c|c|}
\hline Transport & LTE & $\mathrm{H} 3 \mathrm{I}$ & LTE TELK & KOMSEL \\
\hline Sumber & Server Blynk & NodeMCU & Server Blynk & NodeMCU \\
\hline Tujuan & NodeMCU & Server Blynk & NodeMCU & Server Blynk \\
\hline IP Source & 188.166.206.43 & 192.168.137.149 & 188.166.206.43 & 192.168.137.149 \\
\hline IP Destination & 192.168.137.149 & 188.166.206.43 & 192.168.137.149 & 188.166.206.43 \\
\hline Jumlah Packet Data yang dikirim & 2028 & 2019 & 2027 & 2011 \\
\hline Jumlah Packet Data yang diterima & 2028 & 2019 & 2027 & 2011 \\
\hline Total Delay $(s)$ & 88.524189 & 297.765428 & 74.52287 & 304.009853 \\
\hline Total Variasi Delay (s) & 0.041376 & 0.029718 & 0.045585 & 0.033321 \\
\hline Packet Data yang diterima (bytes) & 109707 & 142482 & 109648 & 141901 \\
\hline Lama Pengamatan (s) & 386.289617 & 386.248241 & 383.240264 & 383.194679 \\
\hline
\end{tabular}

Tabel 4. Data hasil capture traffic pada bagian hardware 
Tabel 5. Data hasil capture traffic pada bagian HMI

\begin{tabular}{|c|c|c|c|c|}
\hline \multirow{2}{*}{$\begin{array}{l}\text { Transport } \\
\text { Sumber }\end{array}$} & \multicolumn{2}{|c|}{ LTE H3I } & \multicolumn{2}{|c|}{ LTE TELKOMSEL } \\
\hline & Server Blynk & HMI Blynk & Server Blynk & HMI Blynk \\
\hline Tujuan & HMI Blynk & Server Blynk & HMI Blynk & Server Blynk \\
\hline IP Source & 188.166 .206 .43 & 192.168 .42 .50 & 188.166 .206 .43 & 192.168 .42 .50 \\
\hline IP Destination & 192.168 .42 .50 & 188.166 .206 .43 & 192.168 .42 .50 & 188.166 .206 .43 \\
\hline Jumlah Packet Data yang dikirim & 1763 & 1752 & 1725 & 1713 \\
\hline Jumlah Packet Data yang diterima & 1763 & 1752 & 1725 & 1713 \\
\hline Total Delay (s) & 79.709651 & 258.002797 & 63.876401 & 267.480171 \\
\hline Total Variasi Delay (s) & 0.035019 & 0.024798 & 0.039501 & 0.041544 \\
\hline Packet Data yang diterima (bytes) & 95483 & 123935 & 93315 & 121178 \\
\hline Lama Pengamatan $(\mathrm{s})$ & 337.712448 & 337.677429 & 331.356572 & 331.317071 \\
\hline
\end{tabular}

Kita ambil contoh untuk perhitungan delay, jitter, throughput dan packet loss saat pengiriman data dari server blynk ke nodeMCU menggunakan transport LTE H3I. Menggunakan data yang ada pada tabel 4. Untuk mendapatkan rata rata delay per packet dihitung, maka didapatkan rata-rata delay untuk pengiriman data dari server blynk ke Node MCU adalah

$$
\begin{gathered}
\text { Rata-rata Delay }=\underset{28.524189 \mathrm{~s}}{2028} \\
\text { Rata-rata Delay }=0.04365 \mathrm{~s}=43.65 \mathrm{~ms}
\end{gathered}
$$

Sedangkan nilai Jitter maka didapat nilai jitter selama proses capture traffic adalah

$$
\begin{gathered}
\text { Jitter }=\frac{0.041376 \mathrm{~s}}{2028-1} \\
\text { Jitter }=0.02 \mathrm{~ms}
\end{gathered}
$$

Nilai packet loss dihitung menggunakan rumus maka didapat nilai packet selama proses capture traffic adalah

$$
\begin{gathered}
\text { Packet Loss }=\frac{2028-2028}{2028} \times 100 \% \\
\text { Packet Loss }=0 \%
\end{gathered}
$$

Nilai througput dihitung menggunakan rumus maka didapat nilai throughput selama proses capture traffic adalah

$$
\begin{gathered}
\text { Througput }=\frac{109707 \text { Bytes }}{386.289617 \mathrm{~s}} \\
\text { Througput }=284.002 \mathrm{Bps}=2272.016 \mathrm{bps}=2.272 \mathrm{kbps}
\end{gathered}
$$

Data hasil pengukuran traffic data lalu kemudian dihitung untuk mencari nilai QoS dihasil kan data pada tabel berikut

Tabel 6. Hasil pengukuran QoS pada bagian hardware

\begin{tabular}{|l|c|c|c|c|}
\hline Transport & \multicolumn{2}{c|}{ LTE H3I } & \multicolumn{3}{c|}{ LTE Telkomsel } \\
\hline Sumber & Node MCU & Server Blynk & Node MCU & Server Blynk \\
\hline Tujuan & Server Blynk & Node MCU & Server Blynk & Node MCU \\
\hline IP Sumber & 192.168 .137 .149 & 188.166 .206 .43 & 192.168 .137 .149 & 188.166 .206 .43 \\
\hline IP Tujuan & 188.166 .206 .43 & 192.168 .137 .149 & 188.166 .206 .43 & 192.168 .137 .149 \\
\hline Delay (ms) & 147.48 & 43.65 & 151.17 & 36.77 \\
\hline Jitter (ms) & 0.01 & 0.02 & 0.02 & 0.02 \\
\hline Throughput (kbps) & 2.95 & 2.27 & 2.96 & 2.29 \\
\hline Packet Loss (\%) & 0.00 & 0.00 & 0.00 & 0.00 \\
\hline
\end{tabular}


Tabel 7. Hasil pengukuran QoS pada bagian HMI

\begin{tabular}{|l|c|c|c|c|}
\hline Transport & \multicolumn{2}{c|}{ LTE H3I } & \multicolumn{2}{c|}{ LTE Telkomsel } \\
\hline Sumber & HMI Smart Phone & Server Blynk & HMI Smart Phone & Server Blynk \\
\hline Tujuan & Server Blynk & HMI Smart Phone & Server Blynk & HMI Smart Phone \\
\hline IP Sumber & 192.168 .42 .50 & 188.166 .206 .43 & 192.168 .42 .50 & 188.166 .206 .43 \\
\hline IP Tujuan & 188.166 .206 .43 & 192.168 .42 .50 & 188.166 .206 .43 & 192.168 .42 .50 \\
\hline Delay (ms) & 147.26 & 45.21 & 156.15 & 37.03 \\
\hline Jitter (ms) & 0.01 & 0.02 & 0.02 & 0.02 \\
\hline Throughput (kbps) & 2.94 & 2.26 & 2.93 & 2.25 \\
\hline Packet Loss (\%) & 0.00 & 0.00 & 0.00 & 0.00 \\
\hline
\end{tabular}

Dari data terlihat pengukuran parameter QoS dalam jaringan saat melakukan pengiriman data pada HMI dan hardware. Hasil yang tampak tidak berbeda jauh jika diaplikasikan pada dua jenis transport yang berbeda yaitu LTE H3I dan LTE Telkomsel. Padahal secara perbandingan speedtest H3I tidak sebagus Telkomsel seperti yang ditunjukkan pada gambar 7. Hal ini dikarenakan kecilnya data yang dikirim, sehingga tidak terlalu membebani jaringan. Rata rata besar paket yang dikirim hanya sekitar 560 bit (Uplink) dan 430 bit (Downlink). Throughput yang terbaca juga sangat kecil dengan rata rata $2.9 \mathrm{kbps}$ (Uplink) dan $2.2 \mathrm{kbps}$ (Downlink).
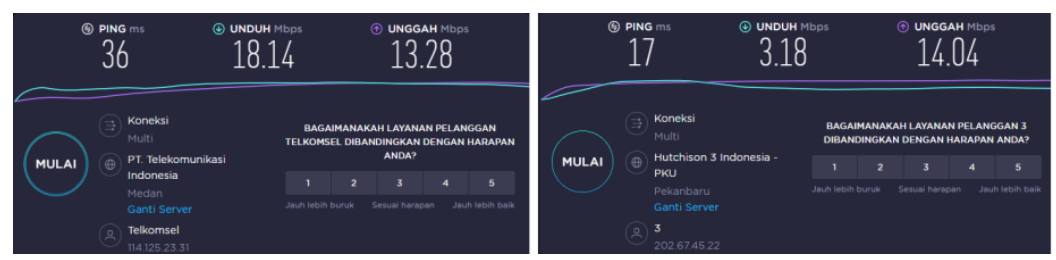

Gambar 4.1. Perbandingan speed test LTE Telkomsel (kiri) dan LTE H3I (kanan)

Dari data parameter QoS diatas juga bisa kita analisa bahwasanya kategori jaringan saat terjadi pengiriman data berada pada tingkat Sangat Bagus karena delay-nya masih dibawah $150 \mathrm{~ms}$, dan jitter nya mendekati 0 , selain itu tidak terjadi packet loss saat pengirim data..

\section{Kesimpulan}

Berdasarkan hasil penelitian dapat di simpulkan bahwa :

a. Berdasarkan dari hasil pengujian, alat dapat berkeja dengan baik untuk mengendalikan Listrik dan memonitoring daya listrik .

b. Penggunaan jaringan jaringan 4G LTE waktu eksekusi yang lebih cepat di bandingkan 3G

c. pengukuran parameter QoS dalam jaringan saat melakukan pengiriman data pada HMI dan hardware yaitu rata rata besar paket yang dikirim hanya sekitar 560 bit (Uplink) dan 430 bit (Downlink).

Throughput yang terbaca juga sangat kecil dengan rata rata 2.9 kbps (Uplink) dan $2.2 \mathrm{kbps}$ (Downlink).

Dan ini bisa dikatakan itu tidak terjadi packet loss saat pengirim data.dan jaringan yang lebih stabil.

\section{Daftar Pustaka}

[1] A. Kadir, Paduan Praktis Mempelajari Aplikasi Mikrokontroller dan Pemrogramannya Menggunakan Arduino. Yogyakarta: Andi Offset, 2013.

[2] Giyartono, A., \& Kresnha, P. E. (2015). Aplikasi Android Pengendali Lampu Rumah Berbasis Mikrokontroler ATmega328. Seminar Nasional Sains dan Teknologi 2015, pp. 1-9.

[3] Karumbaya, A., \& Satheesh, G. (2015). IoT Empowered Real Time Environment Monitoring System.International Journal of Computer Applications, 129(5), 30-32.

[4] P. Seneviratne, Hands-On Internet of Things with Blynk: Build on the power of Blynk to Configure Smart Devices and Build Exciting IoT Projects. Birmingham: Packt Publishing, 2018.

[5] R. Singh, A. Gehlot, V. Jain, and P. K. Malik, Handbook of Research on the Internet of Things Applications in Robotics and Automation. Pennsylvania: IGI Global, 2020.

[6] M. Schwartz, ESP8266 Internet of Things Cookbook. Birmingham: Packt Publishing, 2017.

[7] H. Yuliansyah, "Uji Kinerja Pengiriman Data Secara Wireless Menggunakan Modul ESP8266 Berbasis Rest Architecture," Electrician, vol. 10, pp. 68-77.2016

[8] ETSI. (1999). Telecommunications and Internet Protocol Harmonization Over Networks (TIPHON); General aspects of Quality of Service $(Q o S)$. Sophia Antipolis: European Telecommunications Standards Institute (ETSI). 
[9] GSM Association. (2014). Understanding the Internet of Things (IoT). London: GSMA Connected Living.

[10] Handarly, D., \& Lianda, J. (2018, November). Sistem Monitoring Daya Listrik Berbasis IoT (Internet of Thing). Journal of Electrical Electronic Control and Automotive Engineering (JEECAE), 3(2), 205-208.

[11] Herandy, G., \& Suprianto, B. (2019). MONITORING BIAYA DAN PENGUKURAN KONSUMSI DAYA LISTRIK BERBASIS ARDUINO MEGA2560 MENGGUNAKAN WEB. Jurnal Teknik Elektro, $8(3), 695-702$.

[12] Mutmainah, A. R., \& Hayaty, M. (2019, October 3). Sistem kendali dan pemantauan penggunaan listrik berbasis IoT menggunakan Wemos dan aplikasi Blynk. Jurnal Teknologi dan Sistem Komputer, 7(4), 161-165. doi:10.14710/jtsiskom.7.4.2019.161-165

[13] Pangestu, A. D., Ardianto, F., \& Alfaresi, B. (2019, Juni). SISTEM MONITORING BEBAN LISTRIK BERBASIS ARDUINO NODEMCU ESP8266. AMPERE, 4(1), 187-197.

[14] D. Satria, Zulfan, Munawir, and T. Hidayat, "Implementation of wireless sensor network (WSN) on garbage transport warning information system using GSM module," J. Phys. Conf. Ser., vol. 1175, p. $12054,2019$. 